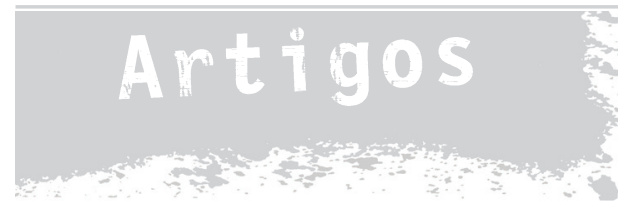

\title{
Entre o Evolucionismo e a Antropologia Social: a Secularização do ritual em Usos e Costumes dos Bantos, de Henri Junod
}

Paulo Gajanigo Na década em que Bronislaw Malinowski desenvolvia o método etnográfico, um (UERJ) missionário suíço, vivendo no sul de Moçambique, publicou um largo trabalho sobre o povo que denominou tsonga. Henri-Alexandre Junod não tinha um método muito definido para lidar com o conjunto da vida social. Tinha, apenas, uma experiência científica fornecida pela entomologia, além da leitura de textos de James Frazer (1956), Edward Tylor (1994), R. R. Marret (1997), Van Gennep (1978) e estudos realizados por outros missionários na África. A etnografia "Usos e Costumes dos Bantu”, publicada entre 1912 e 1913, foi uma tentativa de entender a vida social dos tsonga como um todo, e colocou, por isso, o desafio de compreender as práticas sociais sem que houvesse um instrumento teórico-metodológico desenvolvido para tanto. Junod não pode ser comparado a Malinowski: não desenvolveu um método próprio e paradigmático. Tentou, à sua maneira, cumprir o objetivo de apresentar um estudo total de um grupo com as teorias que tinha em mão. Por ter obtido sucesso (sua monografia foi saudada por importantes antropólogos), o estudo da obra de Junod nos parece bastante estimulante para visualizar as tensões entre as perspectivas da antropologia tida como evolucionista e a nascente antropologia social.

Junod ficou conhecido na história da antropologia, principalmente, por protagonizar um debate com Radcliffe-Brown acerca da relação entre o "irmão da mãe" e o "filho da irmã". Na historiografia da disciplina, ele foi considerado, de maneira geral, um evolucionista, em grande medida, por ter servido como representante da aplicação da "história conjectural" na argumentação de RadcliffeBrown'. Não trataremos dessa questão que, ao nosso ver, deve ser questionada por sua excessiva generalização, mas, no mesmo sentido, defendemos aqui que a obra de Junod serviu e ainda pode servir para uma antropologia social, fundamentada no método etnográfico. De alguma maneira, buscamos, ao mesmo tempo, ressaltar a importância de sua obra pouco conhecida no Brasil2 ${ }^{2}$, apesar de, como trataremos no final do artigo, ser referência para importantes antropólogos. 


\section{JUNOD, EVOLUCIONISMO E MISSÃO SUÍÇA}

Os estudos de sociedades chamadas de "primitivas" no final do século XX estavam marcados pela história conjectural e pelo mentalismo. Tylor, Frazer e Marret, entre outros, buscaram comparar a sociedade ocidental com as que passaram a ser conhecidas por relatos de viajantes, missionários, administradores coloniais, por meio de uma abordagem não propriamente social. Apoiaram-se no estudo de procedimentos mentais da magia e da religião para desenvolver teorias sobre o nascimento e desenvolvimento do pensamento e da prática humana. Evans-Pritchard (1978) e Marvin Harris (1968) chamaram esse método de mentalismo. Os saberes e práticas nessas sociedades eram isolados do conjunto social e recolocados de forma artificial numa perspectiva evolucionista, o que foi chamado, negativamente, de "história conjectural". Com os estudos mais detalhados e profissionais dessas sociedades e com o desenvolvimento, nas universidades, de uma conhecimento propriamente sociológico (ressalta-se o papel da escola durkheimiana), dão-se as principais condições para o surgimento da antropologia social. No entanto, essa passagem não se fez de forma abrupta, como esperamos demonstrar na análise da obra de Junod. No caso do presente artigo, apresentaremos a tensão entre essas perspectivas no âmbito da discussão sobre o estudo dos rituais - elemento-chave no estudo de Junod.

Essa "etnografia completa", como indicou Malinowski (Junod 1944 vol.I:6), só pôde obter tal rótulo por uma articulação complexa dos diversos dados etnográficos recolhidos nas duas dezenas de anos vividos por Junod no sul de Moçambique quando foi figura destacada da Missão Suíça ${ }^{3}$. Junod não foi um etnógrafo profissional, porém, sua posição de missionário, seu interesse científico e o contexto específico em Moçambique foram fatores que o ajudaram a apresentar uma etnografia num patamar superior à média dos relatos de viajantes e missionários.

Em boa parte do tempo, Junod esteve ocupado na missão protestante com as tarefas de evangelização. Para tanto, teve de estudar a língua vernácula, ajudar na sua sistematização para a tradução da bíblia, assim como analisar as raízes culturais da população para que se pudesse formular maneiras de inserção de práticas e crenças cristãs. Sua obra abriga uma mistura entre objetivos de compreensão gerais do modo de vida dos tsongas, e nesse aspecto, ele busca o diálogo com as principais referências científicas do seu tempo, notadamente James Frazer, e de conclusões práticas de "reforma" dos costumes em direção à vida cristã. Nota-se, no entanto, que Junod se preocupa em dividir as análises nesses dois campos na obra (no final dos volumes ele inclui o que chamou de "conclusões práticas", onde declaradamente aponta para as preocupações e julgamentos das condutas dos tsongas). Apesar de não ser nossa preocupação, indicaremos ao longo do artigo que ele não obtém um pleno sucesso nesse aspecto, já que a própria sistematização dos costumes tsonga é marcada pela preocupação em encontrar pontos de contato que facilitariam a evangelização.

O contexto colonial - que impôs uma grande mobilidade populacional; migrações constantes dos jovens; guerras entre os nativos e os brancos, ou mesmo entre nativos; além da imposição de condutas através de leis pelo governo colonial português - não se apresentava como um terreno fértil para a realização do tipo de estudo pretendido pelo missionário. Seu grande objetivo era sistematizar a "cultura tsonga" para ela servir de relicário 
ao próprio povo que a concebeu (Ibidem: 28-29). Essa posição de reconstruir a cultura tsonga conformou uma ambiguidade, que percorre toda a obra de Junod, entre a busca por reformas "civilizacionais" e uma atração pelas particularidades culturais tsongas em relação à cultura européia. A antropóloga moçambicana Tereza Cruz e Silva (2001: 47) identifica que a guerra entre chefes locais e o governo português foi um fator decisivo para que a Missão Suíça se aproximasse de fato dos africanos, já que a própria Missão foi vista como inimiga pelo governo português, posição incentivada pela Igreja Católica, que buscava a hegemonia religiosa em território português. Esse contexto criou um ambiente de colaboração e confiança, muitas vezes, entre missionários e nativos, que se expressa em Junod no interesse de resgatar e sistematizar o conjunto da cultura tsonga ${ }^{4}$.

\section{RITUAL, RELIGIÃO E MAGIA EM JUNOD}

Para delimitar a "tribo tsonga", Junod usou o critério da língua. Porém, com ela não se poderia unificar as práticas dos indivíduos. Era, portanto, necessário que uma linha reunisse todas essas práticas, pensamentos, instituições. Junod teve de buscar outro caminho.

O plano que pretendo adotar é esse: depois de explicar resumidamente, em um capítulo preliminar, o que é a tribo tsonga, pego em um indivíduo e sigo-o sempre, durante toda a sua vida, desde o nascimento até a morte.

A história da evolução de um homem e depois de uma mulher constituirá primeira parte deste livro (Ibidem: 27).

Do nascimento à morte, muitas fases se sucedem: o período de amamentação, a juventude, a puberdade, o casamento, a idade madura e a velhice. Junod apresentou essas fases como se acompanhasse realmente um indivíduo, caminhando pelos anos, vencendo desafios, descobrindo novos e envolto por dilemas. Foi assim que encontrou no ritual um momento privilegiado para descrever e compreender a relação entre indivíduo e sociedade tsonga. Pois são nesses momentos em que a sociedade e o indivíduo se apresentam distintamente. Mais do que isso, são nos rituais que marcam passagens das fases vividas por um indivíduo ou por uma instituição que Junod encontrará seu mais importante material etnográfico. Em uma palavra, se a língua foi-lhe fundamental para delimitar e definir o "povo tsonga", o ritual, particularmente o ritual de passagem, foi a categoria de análise básica para unir as práticas dos falantes tsongas.

O conceito de ritual de passagem fundamentou-se numa visão de sociedade fragmentada e ao mesmo tempo totalizante, como fica explícita nas primeiras palavras de Van Gennep em Les Rites de Passage (1978 [1909]): “Toda sociedade geral contém várias sociedades especiais, que são tanto mais autônomas e possuem contornos tanto mais definidos quanto menor o grau de civilização em que se encontra a sociedade geral." (1978: 25) É na dinâmica entre sociedade geral e sociedades específicas, segundo Van Gennep, que o ritual de passagem obtém sua razão de ser. Numa sociedade em que se encontrariam sociedades mais autônomas, o indivíduo movimenta-se pelo espaço através de demarcações e passagens.

Entre os tsongas, Junod não encontrou essas sociedades específicas tão claramente demarcadas. Suas análises de descrições de rituais basearam-se mais em situações de passagem do que em ilustração das divisórias 
entre sociedades menores. Ainda assim, sua descrição mais nítida do ritual de passagem, não por acaso, foi relativa à escola de circuncisão dos tsongas - uma verdadeira "sociedade específica", afastada inclusive geograficamente da aldeia ${ }^{5}$. Nessa análise podemos perceber nitidamente a utilização das categorias, cunhadas por Van Gennep, de passagem, período marginal, ritos de separação e agregação.

Junod dividiu os ritos da escola de circuncisão em três séries que obedecem, consequentemente, a três momentos indicados por Van Gennep: os ritos de separação; os ritos de margem; e os ritos de agregação. No primeiro momento, os meninos saem da aldeia em companhia dos rapazes circuncidados na escola anterior, que terão o papel de servidores e guardas dos novatos (1996 vol.l:88). A saída da aldeia é, para Junod, o primeiro rito de separação, seguido por outros ritos realizados no caminho para o sungi (escola de circuncisão), que exigem do iniciado a capacidade de lidar com a dor.

Entre as duas fileiras deixa-se uma passagem. Os rapazes recebem então copiosas varadas (a flagelação é também, muitas vezes, um rito de separação). Depois de submetidos a esta experiência inesperada são agarrados no outro extremo da passagem por quatro homens que os despojam de todo o vestuário. Os cabelos são cortados (evidentemente para mostrar que se separam inteiramente do passado) e em seguida conduzem-nos junto de oito pedras onde os obrigam a sentarem-se. (...) Em frente delas há outras oito pedras em que estão sentados oito homens. São os Nyahambe, os Homens-Leões (...). Logo que o rapaz tomou o seu lugar numa pedra, em frente do Homem-Leão, recebe uma pancada por trás; volta a cabeça para ver quem lhe bateu e avista um dos pastores que escarnece dele. O operador aproveita este momento, enquanto a atenção do rapaz está assim desviada, o operador agarra o prepúcio e corta-o com dois movimentos. (/bidem:89)

A ablação do prepúcio é, para Junod, um rito de separação por excelência. Trata-se de uma separação física de uma parte do corpo, representando a vida que o iniciado deixou para trás ao se dirigir ao sungi. Assemelhase bastante às palavras de Van Gennep: “Cortar o prepúcio equivale exatamente a arrancar um dente (...). Com estas práticas retira-se o indivíduo mutilado da humanidade comum mediante um rito de separação (...) que automaticamente o agrega a um grupo determinado" (1978:74-75).

Dá-se, então, o período marginal. Os iniciados viverão por cerca de três meses num recinto distante da aldeia proibidos de ter contato com pessoas à exceção dos homens que já foram iniciados. A alimentação provida pelas mães dos iniciados, por exemplo, é entregue sem que haja contato. Elas caminham diariamente até uma parte do percurso da escola e deixam as marmitas de comida ao chão, dão um sinal e vão embora. Só depois as marmitas são levadas para dentro da escola pelos "pastores", como denomina Junod os homens já iniciados (1996 vol.l:91).

Nesse período se impõem vários tabus, o principal é o tabu sexual. O curioso, como atenta Junod, é o contraste entre essa forte proibição e o uso deliberado da linguagem obscena durante esse período. “Quando as mulheres levam os alimentos até perto da entrada do sungi, os pastores que os vão buscar podem dirigir a essas mulheres toda a espécie de palavras impuras que quiserem. As próprias mães têm o direito de cantar canções obscenas quando pilam o milho para o sungi." (/bidem:92) Trata-se de uma característica patente do período de margem, como já mostrara Van Gennep, quando a ordem é suspensa e novos tabus são impostos. 
Durante os três meses, são introduzidos aos iniciados fórmulas secretas, além de aprenderem o ofício da caça. Há um largo uso de termos estrangeiros no sungi, desconhecidos pelos não-iniciados. Essas fórmulas não podem ser transmitidas fora deste recinto, e é uma maneira de reconhecimento de um iniciado no cotidiano da aldeia. Para Junod, essas fórmulas têm por finalidade aumentar a impressão de mistério da escola. "Os ritos do período de margem são calculados para dar aos candidatos a impressão de que são homens novos e de que devem prová-lo, submetendo-se virilmente a todas as provas desta dura e às vezes cruel iniciação." (/bidem:93)

A marca da passagem imprime-se em sucessivas provações. Os iniciados recebem pancadas diariamente por mais de uma hora, além das pancadas avulsas que levam ao fracassarem nas atividades propostas pelos pastores; dormem ao relento (/bidem:94); nenhum gole d'água é permitido aos iniciados durante todo o período da escola; a alimentação é precária, composta somente de farinha de milho. Essa soma de provações pode levar alguns iniciados a um estado de saúde lamentável e até a morte (Ibidem:96). Se isso ocorre, o infeliz é enterrado em terreno úmido - tal como um bebê quando falece antes do cordão ter sido atado, ou seja, morre como se não fosse ainda uma pessoa.

O período de margem, portanto, não parece nada agradável a esses meninos que aguardam ansiosamente pelos últimos dias, quando ocorrem os ritos de agregação. O primeiro deles tem lugar em todas as últimas manhãs da escola.

Na extremidade acha-se um homem, meio escondido numa massa circular branca parecida com lã ou cabelo. Acordam os rapazes, e os pastores conduzem-nos para o pátio. Fazem-nos deitar de costas, cabeças voltadas para o mastro que se chama mulagaro, e fazem-nos dizer: "Bom dia, avô". Então, uma voz vinda do alto do mastro responde-Ihes: “Eu vos saúdo, meus netos" (...). A significação deste rito é clara: os candidatos são postos em comunicação com o velho que representa o clã; é o princípio da participação na vida dos adultos da tribo. (Ibidem:101)

Como parte desses ritos, há também um que busca, segundo Junod, a purificação através da ingestão de medicamentos pelos iniciados. “Este rito assemelha-se mais a um rito de separação que de agregação. Encontramos muitas vezes no fim de períodos de margem ritos de separação. Significam a separação do próprio período de margem, o qual implica uma espécie de poluição que deve ser apagada". (Ibidem:101)

Já preparando a volta dos circuncidados à aldeia, uma dança se sucede com os iniciados mascarados, com a identidade preservada, tendo, como público, as mulheres da aldeia. Depois, já no último dia, todos os materiais usados na escola são reunidos, alguns homens tacam-lhe fogo, "o grupo dos circuncisos, rodeado dos pastores e dos homens, dirige-se correndo para um lago sem olhar para trás (separação do sungi, do período de margem). Se olhassem o que se passava atrás de si, teriam os olhos varados e ficariam para sempre cegos!" (Ibidem:102)

Daí se dirigem para a capital do chefe, onde realizam uma entrada solene.

Cobertos de ocre eles marcham sobre esteiras estendidas no chão para que os seus pés não toquem a poeira; avançam lentamente, curvados, estendendo primeiro uma perna depois a outra num movimento vivo, tentando imitar a marcha do camaleão - o sábio, o prudente. Daí em diante são homens que pensam e não rapazes 
desprovidos de inteligência. Depois de todos se sentarem em silêncio na praça central da capital, com as cabeças ainda inclinadas para o chão, as irmãs e as mães vindas de todas as aldeias devem ir reconhecê-los. Cada mulher leva consigo um bracelete, ou um xelim, ou qualquer pequeno presente, e procura o seu filho na multidão. Quando supõe tê-lo encontrado, beija-o na face e oferece-lhe o seu presente. Os rapazes empunham duas varas. Uma tem alguns pequenos ramos laterais em que penduram os braceletes (vusenga) que lhes dão. A outra é menor; quando a mãe encontra o filho e o beija, ele toca-lhe com ela-levemente se é a mãe ou a avó; com muito mais força se é a irmã - ao mesmo tempo, pronuncia o novo nome que escolheu. Em resposta a esta demonstração, a mãe põe-se a dançar e a cantar o louvor do seu filho! É um rito de agregação típico, chamado o kukunga - a ruptura do silêncio - que encontraremos por mais de uma vez nos ritos de passagem da tribo. (/bidem:102-103)

Nos rituais relacionados à escola de circuncisão, Junod parece ter encontrado a situação social perfeita para aplicar as categorias cunhadas por Van Gennep. Pôde identificar nitidamente as várias fases da escola de circuncisão, utilizando apenas essas categorias, sem recorrer, portanto, a conceitos provindos diretamente do mentalismo corrente no evolucionismo. Porém, esse não é o único caso em que Junod aplicou a ideia de passagem, tampouco foi a única forma com que analisou os rituais.

No decorrer da etnografia, a análise dessas situações se mostra mais complexa e heterodoxa. Faz-se sentir a influência direta de autores como Tylor, Frazer e Marett, pela qual o formalismo marcante do procedimento de Van Gennep perde espaço. A abordagem mais formal do ritual em Junod encontra-se dispersa em toda a sua etnografia. De outro lado, a abordagem referenciada na análise mentalista encontra-se mais concentrada, apesar de podermos ver elementos dispersos ao longo da etnografia, no seu estudo sobre a religião e a magia dos tsongas. Esse trecho constitui uma curiosa oportunidade de observarmos teorias, formuladas num estágio anterior ao desenvolvimento do método etnográfico, serem aplicadas por Junod através de um modo de se realizar pesquisa que possibilitou a base para a demolição dessas próprias teorias. Gostaria de me estender um pouco na exposição das análises de Junod sobre o pensamento religioso tsonga para demonstrar como essas teorias sofreram com a aplicação eclética do missionário e como isso se deveu principalmente por estar Junod preocupado também com a prática ritual.

Para Junod, haveria, entre os tsongas, três grupos de crenças e práticas mágico-religiosas: a ancestrolatria, o monoteísmo e a prática da adivinhação. A ancestrolatria seria a religião mais difundida e presente na vida tsonga. Para o pensamento desse grupo, concebe-se que todo indivíduo, quando morre, continua com seu espírito no mundo. Esse espírito denominado xikwembu, após a morte, passa a ser encarado como uma divindade, um antepassado-deus.

Junod não vê a ancestrolatria como uma religião bem sistematizada, apesar de estar constantemente presente na vida tsonga. A principal ideia sobre os antepassados-deuses é a de que moram em bosques sagrados, onde são enterrados os chefes da tribo. Esses bosques são interditados aos homens, apenas é permitida a entrada de um guardião, descendente do antepassado lá enterrado. A proibição é reforçada por diversas histórias assustadoras que os tsongas contam sobre pessoas que invadiram a área do bosque, ou que colheram frutos de suas árvores, e, por esses atos, foram perseguidas pelos espíritos ou sofreram infortúnios. 
$O$ relacionamento dos vivos com esses antepassados ocorre através de sacrifícios e preces. Existe um termo nativo que, para Junod, pode ser entendido como sacrifício ou oferenda: o mhamba ${ }^{6}$ é definido como "todo o objeto, ato ou pessoa que se emprega para estabelecer uma ligação entre antepassados-deuses e os seus adoradores" (1996 vol.II:359). Junod se utiliza de uma definição ampla porque lida com algo de fato amplo, mhamba pode tanto significar objetos utilizados em dádivas a esses deuses como também referem-se a objetos utilizados em ações mágicas. Pois os sacrifícios que se estabelecem para os antepassados-deuses não podem ser classificados como atos simplesmente religiosos.

A magia apareceria nesses ritos a partir de ações baseadas em axiomas da mentalidade primitiva, seriam estes muito próximos aos dos definidos por Frazer, porém com variações: “o semelhante age sobre o semelhante e produz o semelhante; a parte representa o todo e age sobre o todo; o desejo expresso produz o resultado desejado" (/bidem:313). O primeiro axioma é quase idêntico ao da lei de similaridade de Frazer, o segundo consiste em uma ampliação da definição da lei de contigüidade, pois Junod argumenta que não é só o contato que liga os objetos ou elementos, como afirmava o pensador britânico, mas há "considerações mais espirituais". Transcrevo o exemplo que o autor usa para ilustrar o argumento:

Por que deve a primeira mulher do caçador encerrar-se na palhota, para salvar seu marido da fúria do hipopótamo? Porque, sendo, como é, a sua verdadeira mulher, a mulher por excelência, ela está unida a ele por uma ligação misteriosa. A comunidade de vida é mais completa entre ela e seu marido que entre o caçador e suas outras mulheres (Ibidem:314)

Junod parece querer dizer que esse tipo de magia baseada no axioma da parte sobre o todo pressupõe, por vezes, não apenas um contato e uma relação direta entre os elementos, mas uma concepção, chamada de misteriosa, ou talvez social, dessa relação. Não é à toa que Junod prefira usar o termo magia "comunialista" ao termo consagrado "simpática" por dar um caráter mais social e menos mentalista à definição. O terceiro axioma ("o desejo expresso produz o resultado desejado") é uma adição aos estabelecidos por Frazer, Junod acredita que a forte hierarquia do grupo social transformou a palavra (primeiramente do chefe) em algo poderoso, fazendo com que se praticasse essa "magia verbal". Como ilustração desses atos mágicos nos ritos do sacrifício, pode-se citar o uso de unhas e cabelos dos chefes falecidos que agem no rito para que os deuses tomem tal atitude desejada.

Junod encontra, então, nos rituais envolvidos na ancestrolatria, práticas que denomina por religiosas, são elas: sacrifícios de animais, bebidas, objetos de valor e, raramente, humanos. Tais práticas têm o objetivo de agradar aos deuses, ou de reparar por alguma ofensa. Para Junod, as oferendas não têm valor real, já que os deuses não consomem as dádivas e nem os "tsongas" abrem mão de consumi-las; têm, somente, um valor religioso, pois são usadas para entrar em relação com os antepassados-deuses. Desse conjunto, Junod viu a ancestrolatria como uma religião pouco desenvolvida. Estaria presente nos antepassados-deuses o caráter divino, trazido pela onipresença e onipotência destes, mas ainda haveria humanidade em demasia nesses antepassados, uma identificação entre os vivos e os deuses que é percebida na falta de respeito e temor dos religiosos frente aos antepassados-deuses, bem 
como na ambigüidade desses deuses que poderiam tanto fazer o bem quanto o mal. Faltaria, para a ancestrolatria, transcendência e moral, presentes nas religiões "elevadas" (monoteístas).

Junod encontra outras crenças que, acredita, não podem ser atribuídas à ancestrolatria. Estariam relacionadas, antes, a uma religião pouco atuante no pensamento tsonga, de forma a constituírem uma série paralela à ancestrolatria. Consistiria numa crença monoteísta que teria como deus o Céu (Tilo). O missionário não esconde a animação em encontrar pistas de monoteísmo entre os tsongas: o encontro com essa concepção religiosa é definida por Junod como "um filão de ouro que foi descoberto graças a certas circunstâncias fortuitas e que se deve explorar com grande cuidado" (Ibidem:367).

Não há muitos ritos e práticas relativas ao Tilo, que se ocupa, principalmente, de grandes fenômenos meteorológicos e cósmicos. Dos poucos campos restantes de atuação do Céu, a chuva parece ser o assunto que apresenta mais indefinição sobre seu verdadeiro poder religioso, pois para conseguir a chuva, os tsongas procurariam o Céu, os antepassados-deuses, como também várias outras forças. A chuva na vida tsonga é uma questão capital, a falta nas estações úmidas significa fome e miséria, é essa importância que, para Junod, faz esse assunto ser envolvido por vários rituais. Segundo Junod, a principal idéia entre os tsongas consistiria em que a chuva seria causada pelos antepassados-deuses, portanto os rituais ganhariam a forma de sacrifícios com a finalidade de Ihes agradar. A magia poderia também atuar para impedir a chuva de cair, isso seria efeito de drogas encantadas manipuladas por deitadores de sorte. Seria possível também que abortos não tratados pelas regras da tribo fossem "causas naturais" da suspensão da chuva, dever-se-ia, então, realizar ritos purificadores para restabelecer a ordem.

Se o achado de elemento monoteísta na crença tsonga agradou os olhos do missionário, pode-se dizer que, com mesma intensidade, a arte da adivinhação impressionou Junod. A complexidade desta prática, a sofisticação de seu saber e, principalmente, o caráter representativo da "vida tribal", fez esse etnógrafo suspirar pelas qualidades do pensamento tsonga.

Segundo Junod, a adivinhação entre os tsongas estaria presente em várias práticas, desde presságios feitos ao se ver animais que significam certo acontecimento na vida de um tsonga, passando por meios para tirar a sorte (semelhantes aos dados), ou estados de êxtase que revelam a localização de ouro escondido, até um sistema complexo que utiliza ossículos. Junod dedica menos de três páginas para descrever os primeiros, no entanto, delonga-se por quase todo o capítulo a explicar a arte de adivinhação através de ossículos. É sobre sua análise desta última prática que, semelhantemente, daremos mais atenção.

Essa arte consiste em jogar os ossículos e interpretar suas posições como um todo, realizando então um prognóstico ou um diagnóstico. Cada ossículo representa um elemento presente na vida social tsonga, relacionado pela semelhança de formato, pelo local e principalmente por analogia. Por exemplo, Junod mostra que os ossículos dos animais domésticos representam as pessoas da aldeia, cada ossículo de animal representa uma pessoa, cargo ou idéia baseado nas características dos animais. Há outros objetos, porém, que não ossos, cuja função é representar idéias e objetos. A interpretação dos ossículos divinatórios obedece a regras resumidas por Junod desta forma: primeiramente, faz-se perguntas sucessivas para saber de quem é a culpa pelo problema causado (caso 
seja uma doença), procurando inicialmente nos parentes do lado paterno e depois do lado materno; dependendo da posição em que caem os ossículos e a relação entre eles, tem-se certo significado que aponta o causa do mal. Para Junod, "o sistema tsonga ultrapassa em muito a engenhosidade dos outros sistemas que [conhece] e responde admiravelmente às necessidades do indígena, porque corresponde a todos os elementos da sua vida e fotografa-os, por assim dizer, de tal maneira que, em todos os casos possíveis, indicações e diretivas podem ser obtidas" (/bidem:464-5) “De tudo quanto precede conclui-se facilmente que a arte dos deitadores de ossículos está longe de ser um jogo de crianças e que não é, também, negócio de charlatões intrujando o semelhante demasiado crédito" (Ibidem:488).

A interpretação dos ossículos, como dito, baseia-se em regras compartilhadas pela população, inclusive as interpretações são discutidas, porém não se trata de uma aplicação de regras matemáticas: estão fundamentadas na imaginação. Não uma imaginação aproveitadora do deitador, mas uma criatividade aceita pela vontade de se saber o futuro. Essa crença, então, na adivinhação, não parece pertencer a uma matriz clara do pensamento tsonga, poderia haver um fundamento religioso, pois os antepassados-deuses foram deitadores de sorte, apesar de os próprios ossículos poderem revelar desejos desses antepassados, "em certo sentido, os ossículos são superiores aos deuses" (Ibidem:489).

A visão e descrição de Junod sobre essas três matrizes mágico-religiosas que apresentei aqui nos possibilitam observar como as categorias de magia e religião - que abrigaram um debate caloroso no evolucionismo clássico foram utilizadas pelo etnógrafo. Vemos um desvio desses conceitos se compararmos à sua formulação no debate evolucionista. Primeiramente, em Junod, a distinção entre magia e religião não pode ser traçada de maneira clara. Os atos mágicos não são resumidos a uma concepção desalmada do mundo, e nem a religião pode ser identificada por apenas exigir a existência de espíritos (Frazer 1956). Ao considerar os rituais, além das crenças, na definição do caráter de certo sistema ou prática, Junod não consegue manter a coerência que percebemos nas definições de Frazer, e torna-se possível afirmar que o ritual da chuva, mesmo evocando um deus, é mágico, ou que sacrifícios, mesmo imerso em crenças mágicas, é religioso. A questão, para Junod, não está simplesmente na crença com a qual se realiza tal ação, mas no sentido geral do ritual. Como diriam, dez anos antes, Mauss e Hubert, ao criticar as delimitações entre magia e religião em Frazer, para definir certa prática é preciso olhar o conjunto de práticas do qual ele faz parte (Mauss \& Hubert 1979:52-3).

Outro elemento desviante que aparece na etnografia é a substituição de alguns termos da teoria mentalista sobre a magia. Junod utiliza o conceito de magia comunalista, em lugar da magia simpática. Uma diferença significativa se olharmos a partir da crescente importância da análise social da prática mágica. A magia simpática pressupõe uma interrelação de efeitos, assim como a comunialista. Porém aquela localiza essa interrelação na similaridade de ideias, objetos ou qualquer característica que é relacionada por associação mental. Diferentemente, a ideia de magia comunialista pressupõe uma associação de elementos distintos a partir das relações sociais. Aquilo que fundamentaria uma ligação entre dois elementos não moraria na mente canhestra de um selvagem, mas nas formas das relações sociais. 
Por último, seu interesse e admiração pela prática da adivinhação reafirmam a busca crescente pela análise social do ritual. A adivinhação, claramente mágica - para o missionário -, possuiria uma concepção da sociedade, e o processo de interpretação de seus resultados levaria em conta o saber sobre a sociedade e suas relações. Dessa forma, a própria magia estaria imbuída pelo saber social e pelo conjunto das relações presentes na tribo

\section{A CONTRIBUICQÃO DE JUNOD}

Como mostram Sally Falk Moore e Bárbara Myerhoff (1977:3), os primeiros estudos antropológicos sobre o ritual estiveram intimamente relacionados às práticas religiosas ou mágicas. Nessa perspectiva, pode-se incluir Tylor, Frazer e Marret. A ruptura epistemológica que teve em Durkheim o mais forte representante não se estendeu diretamente para uma secularização do ritual, mas abriu caminho para tal. Robert Bellah (2008:200) argumenta que já n'As Formas Elementares da Vida Religiosa, o autor permite uma leitura que identifique na vida secular práticas ritualizadas. No entanto, Durkheim, formalmente, ainda define o ritual como prática referente ao sagrado.

Marcel Mauss, membro da escola durkheimiana, foi o que mais precocemente tratou o ritual de forma secular. Desde o começo de sua carreira, segundo Roberto Cardoso de Oliveira (1979:24), Mauss pensava os costumes em geral como o objeto da antropologia, e não uma parte específica ligada ao pensamento mágico ou religioso. Em seu texto sobre "A Prece" (1909), Mauss não mais insistirá na divisão entre sagrado e profano (Karady 1968:XLIII), e assim abrirá campo para seus estudos posteriores sobre práticas rituais seculares.

Nada indica que Junod tenha lido à época Mauss ou Durkheim. Como dissemos, sobre o tema dos rituais, sua influencia principal é Van Gennep, uma figura ambígua, marcado tanto pelo mentalismo quanto pela análise social do ritual. Como aponta Da Matta,

Van Gennep foi provavelmente o primeiro a tomar o rito como um fenômeno a ser estudado como possuindo um espaço independente, isto é, como um objeto dotado de uma autonomia relativa em termos de outros domínios do mundo social, e não mais como um dado secundário, uma espécie de apêndice ou agente específico e nobre dos atos classificados como mágicos pelos estudiosos. (1978:12)

No entanto, Les Rites de Passage não se apresentou como uma crítica ao acúmulo teórico sobre o ritual gerado pelos mentalistas. Na verdade, se acompanharmos as primeiras páginas de seu livro, veremos uma estranha junção de conceitos das duas abordagens distintas de ritual. Para Van Gennep, haveria dezesseis combinatórias de ritos que variariam segundo as seguintes categorias: dinamismo-animismo; positivo-negativo; simpáticos-de contágio; diretos-indiretos. São classificações que consideram fundamentalmente o conteúdo do rito, e não sua forma. Sem se confrontar diretamente com essas categorias, e até reproduzindo-as, o autor chama atenção para outro elemento: o mecanismo do rito. A análise dos mecanismos formais do rito vai então ganhando espaço no texto e, nas palavras de Da Matta, 
é possível perceber nitidamente como a visão tipológica, apresentada logo nas primeiras páginas do livro, cede lugar a uma visão estrutural, fundada não mais numa classificação exclusiva e complicada de tipos de rituais, mas em princípios organizatórios, dos quais a necessidade de incorporar o novo, reduzir a incerteza e realizar a passagem de posição, num deslocar constante, é fundamental. (1978:17)

O movimento e a tensão vistos em Les Rites de Passage são, creio, bastante semelhantes ao que pode ser observado na etnografia de Junod, porém, obviamente, perceptível de maneira mais árdua, por não ser um livro de síntese, como é o caso da obra de Van Gennep. No que se refere à visão secular do ritual, Van Gennep ainda define o ritual de passagem como uma forma de se passar por limites que separam o profano e o sagrado ${ }^{7}$, fala, ao tratar dos ritos de iniciação, de "rotação do sagrado":

O sagrado, de fato, não é um valor absoluto, mas um valor que indica situações respectivas.(...) Assim, alternadamente, conforme nos coloquemos em uma posição ou em outra da sociedade geral, há um deslocamento dos 'círculos sagrados'. (1978:32-33)

Nesse sentido, Junod tem uma contribuição para além de Van Gennep. Como afirmou Gluckman, “Junod also used this schema [rites de passage], sometimes implicitly, but mostly explicitly, to describe and discuss not only other Tsonga rituals but also much of Tsonga secular life". (1966:8-9) Como toda a contribuição deste missionário, o aspecto ressaltado por Gluckman encontra-se perdido pelas narrativas etnográficas do missionário. Não encontramos, portanto, uma análise anunciadamente secular do ritual, mas sim o resultado de um uso deliberado do conceito de "rito de passagem" em quase todas as fases críticas da vida social dos tsongas.

Mesmo na própria descrição da escola de circuncisão detalhada mais acima, vemos uma abordagem não focalizada na relação com o sagrado, mas no procedimento pelo qual se opera uma mudança de status ${ }^{8}$. Para Junod, o rito de passagem pelo qual são submetidos os jovens tsongas, ao contrário do batismo cristão que significaria a entrada numa comunidade santa, "ignora completamente esta idéia moral e espiritual" (1996 vol.l:469). Portanto, "o fim da escola de circuncisão é, principalmente, introduzir o rapazinho na idade viril, purificá-lo do vukhuna, fazer dele um membro adulto e consciente da comunidade" (/bidem, 104) ${ }^{9}$.

Em outras práticas, percebemos a ausência de uma ideia de sagrado nessa interpretação de Junod, apesar da utilização da ideia de passagem. Um caso interessante é o dos ritos de guerra - os procedimentos pelos quais passam os guerreiros tsongas durante uma batalha são os mesmos, segundo Junod, que os vistos na escola de circuncisão e nos ritos de luto. Durante o conflito, toda a povoação deve observar severos tabus, como a proibição de relações sexuais em toda a povoação. “O período das hostilidades parece ser verdadeiramente considerado como um período à margem para toda a tribo". (/bidem:425). Tal semelhança chega a causar espanto no próprio missionário: "Não é impressionante ver a correspondência que existe entre estes ritos, com a sua seqüência particular, e os da escola de circuncisão, do luto, e da mudança de uma aldeia?" (Ibidem:426).

Portanto, creio, fazendo coro com as palavras de Gluckman, ser essa a contribuição de Junod para a teoria 
ritual na antropologia, que deve ser localizada na sua utilização extensiva do conceito de "ritual de passagem" que se mostrou fértil ao se deparar com a vida social dos tsongas. Junod pôde, assim, explorar alguns limites do conceito. A visão mais formalista desse conceito permitiu ao missionário se desfazer, por vezes, da necessidade de um elemento sagrado no ritual. Explorou o rito de passagem como um procedimento, desenvolvendo as potencialidades do trabalho ímpar e criativo de Van Gennep.

Uma demonstração desse argumento pode ser encontrado ao percorrermos o caminho traçado pelas referências ao Usos e Costumes dos Bantos. A despeito de sua contribuição à discussão do estudo do parentesco, as referências à obra de Junod se restringem à aplicação do conceito de "rito de passagem". Gluckman, certamente, foi um dos antropólogos que leram o trabalho de Junod com mais atenção (Cabral 1996:26). Victor Turner também foi um leitor minucioso da obra (Engelke 2000:845). Em ambos podemos entender o interesse e o impacto provocados pelas descrições de Junod dos ritos de passagem. Ambos os autores tiveram um papel central na transfiguração da ideia do rito de passagem para a análise da vida social mais ampla, para a compreensão dos conflitos inerentes às novas relações sociais forjadas no contexto colonial africano. Em Turner, por exemplo, vemos a transformação da categoria de "período marginal" em algo mais amplo, para além de uma existência ritual, marcando um processo comum presente em sociedades variadas, inclusive na sociedade ocidental moderna (Turner 1974). Como coloca sinteticamente João de Pina Cabral, "Vemos assim surgir uma nova concepção de liminaridade, que não a identifica exclusivamente com os processos de transição, mas abrange também as formas de conceber os fenômenos marginais ou antiestruturais" (1996:32).

A Pina Cabral, por sua vez, deve-se atribuir um papel semelhante ao que foi forjado por Gluckman, com a ressalva do período que atuou. $\mathrm{O}$ antropólogo português resgatou o trabalho de Junod para indicar a contribuição de seu pensamento para o conceito de liminaridade. Caracterizou, em sintonia com Gluckman, o estudo de Junod como um passo a mais ao que fora dado por Van Gennep, e atribui tal feito ao desenvolvimento de categorias propriamente sociais (1996:29).

Dois pontos, creio, servem-nos como conclusão. Primeiro, a pouco conhecida obra de Junod, em particular no Brasil, pode ser objeto de estudo da antropologia social, já que apresenta reflexões relevantes que ainda dialogam com o estágio atual das pesquisas, principalmente, na temática dos rituais seculares. Por fim, a etnografia Usos e Costumes dos Bantos demonstra que a transição da abordagem mentalista ao foco de análise social não foi linear nem abrupta; mesmo autores que apresentam perspectiva claramente evolucionista (Junod partia da ideia de uma linha evolutiva da cultura) podem apresentar reflexões e categorias de análise férteis para uma perspectiva não evolucionismo e fortemente social. 
1 No famoso artigo "The mother's brother in South Africa", escrito em 1924, Radcliffe-Brown critica a explicação dada por Junod para o comportamento lícito e íntimo entre o irmão da mãe e o filho da irmão entre os tsongas. Junod argumenta que essa intimidade pode ser explicada como uma sobrevivência de um período anterior de matriarcado. Daí a atribuição de Junod como partidário da "história conjectural". Radcliffe-Brown, usando das próprias descrições de Junod, propõe uma explicação sincrônica, negando a busca por explicações que não poderiam ser encontradas dentro da estrutura social. O debate foi visto como um clássico do confronto entre a nascente antropologia social, e particularmente o estrutural-funcionalismo, com o evolucionismo. Em minha dissertação, discuto como isso obscureceu várias sutilezas que impedem uma definição tão rígida de Junod, mesmo no que diz respeito ao tema do parentesco. Para um aprofundamento dessa discussão, ver Gajanigo 2006, especialmente, o capítulo I da segunda parte "'O irmão da mãe' de Junod".

2 Parte desse objetivo se deu com a publicação, pelo Instituto de Filosofia e Ciências Humanas da Unicamp, do vol. I de Usos e Costumes do Bantos em 2009.

3 O que chamo de Missão Suíça possuiu vários nomes, entre os quais destacamos Mission des Églises Libres de la Suisse romande (Mission romande), denominação que tinha em 1883, e Mission Suisse Romande, nome que receberá em 1917 (Butselaar 1984).

4 George Stocking, ao comentar sobre a passagem da antropologia evolucionista para a que chama de sociocultural, aponta que no âmbito político, a crítica ao evolucionismo parte já de um período mais avançado do colonialismo, onde a questão da completa assimilação é questionada, dando cabo a uma resposta romântica de preservação das culturas (1987: 289). Junod, de fato, afirmava que os africanos deveriam se adaptar às novas situações de vida, modernizar-se. No entanto, ressaltava que deveriam fazer de forma própria, através de sua própria cultura (1996, vol.II: 534). Sobre a posição de Junod frente a preservação da cultura tsonga, ver Gajanigo 2006:36-7.

5 Segundo Junod, os meninos que somavam seus 10 a 16 anos, ou mesmo os adultos que por algum motivo - como estarem trabalhando nas minas na África do Sul - não puderam ser circuncidados, dirigiam-se à escola de circuncisão que era realizada com uma frequência de 4 ou 5 anos.

6 Sobre a caracterização do mhamba, Junod só a realizou na segunda versão de Life in a South African Tribe, ou seja, a que foi traduzida para o francês e posteriormente para o português, sendo essa a que estudamos.

7 Como afirma Terence Turner, a concepção do ritual como transição entre profano e sagrado foi fortemente influenciada pelo texto de Mauss e Hubert sobre o sacrifício e ainda pelo trabalho de Robertson Smith - um precursores na análise social do ritual (Turner 1977:69).

8 Apesar de em Van Gennep quase todos os dados apresentados serem de cerimônias mágico-religiosas, encontra-se um dado sobre a iniciação profissional do artesão (1978: 95), o que aponta Van Gennep é que há um princípio subjacente no ritual de passagem que também influencia outros procedimentos, como o citado. Ou seja, Van Gennep dá uma chave fundamental aqui para a utilização do esquema indicado do ritual para eventos seculares.

9 O fim de purificar o iniciado do vikhuna não significa que tem um sentido sagrado, pois, segundo Junod, o vukhuna é simplesmente o estado de um jovem que ainda não foi circuncidado, sendo considerado um ser incompleto (1996, Vol.I: 74). 


\section{REFERÊNCIAS BIBLIOGRÁFICAS}

BELLAH, Robert. 2008. “Durkheim and Ritual”. In Jeffrey Alexander \& Philip Smith. The Cambridge Companion to Durkheim. Cambridge: Cambridge University Press.

BUTSELAAR, Jan Van. 1984. Africains, Missionnaries et Colonialistes - les origines de l'Église Presbytérienne du Mozambique (Mission Suisse), 1880-1896. Leiden: E. J. Brill.

CABRAL, João de Pina. 1996. “A Difusão do Limiar". Mana 2(1): 25-57.

CARDOSO de OLIVEIRA, Roberto. 1979. “Introdução a uma leitura de Mauss”. In Marcel Mauss. São Paulo: Ática.

CRUZ E SILVA, Teresa. 2001. Igrejas protestantes e consciência política no Sul de Moçambique. O caso da Missão Suíça (1930-1974). Maputo: Promédia.

DA MATTA, Roberto. 1978. “Os ritos de passagem de Arnold Van Gennep e o limiar da antropologia moderna”. In A. Van Gennep. Os Ritos de Passagem. Petrópolis: Vozes.

DURKHEIM, Émile. 1996. As Formas Elementares da Vida Religiosa. São Paulo: Martins Fontes.

ENGELKE, Matthew. 2000. "An interview with Edith Turner". Current Anthropology 41(5): 843-852.

EVANS-PRITCHARD, E. E. 1978. Antropologia Social da Religião. Rio de Janeiro: Editora Campus.

FRAZER, Sir James. 1956. La Rama Dorada. México D.F.: Fondo de Cultura Económica.

GAJANIGO, Paulo. 2006. O Sul de Moçambique e a História da Antropologia: Os Usos e Costumes dos Bantos, de Henri Junod. Dissertação de Mestrado. Campinas: Unicamp.

GLUCKMAN, Max. 1966. Essays on the ritual of social relations. Manchester: Manchester University Press.

HARRIS, Marvin. 1968. The Rise of Anthropological Theory: a history of theories of culture. New York: Thomas Y. Crowell. JUNOD, Henri-Alexandre. 1944. Usos e Costumes dos Bantos. Vol. I. Lourenço Marques: Imprensa Nacional de Moçambique. . 1996. Usos e Costumes dos Bantu. Tomo I e II. Maputo: Editora do Arquivo Histórico de Moçambique.

KARADY, Victor. 1968. “Présentation de I'édition”. In Marcel Mauss. Oeuvres. Volume I. Paris: Les Éditions de Minuit.

MARETT, R.R. 1997. “Threshold of Religion”. In Bryan S. Turner (org.). The Early Sociology of Religion, vol. VII. Witshire: Routledge/Thoemmes Press.

MAUSS, Marcel \& HUBERT, Henri. 1979. "Esbozo de uma teoria general de la magia”. In Marcel Mauss. Sociologia y Antropologia. Madrid: Editorial Tecnos.

MOORE, S. F.; MYERHOFF, B. G. 1977. "Secular Ritual: forms and meanings". In Moore \& Myerhoff (orgs.). Secular Ritual. Assen/Amsterdam: Van Gorcum.

STOCKING Jr., George. 1987. Victorian Anthropology. New York: The Free Press.

TURNER, Victor. 1974. O processo ritual: estrutura e anti-estrutura. Petrópolis: Vozes.

TURNER, Terence. 1977. “Transformation, Hierarchy and Transcendence: A Reformulation of van Gennep's Model of the Structure of Rites of Passage". In Moore \& Myerhoff (orgs.). Secular Ritual. Assen/Amsterdam: Van Gorcum.

TYLOR, Edward Burnett. 1994. “Primitive Culture”. In George Stocking Jr. The collected Works of E. B. Tylor, vol. V. Wiltshire: Routledge/Thoemmes Press.

VAN GENNEP, Arnold. 1978. Os Ritos de Passagem. Petrópolis: Vozes. 


\section{Entre o Evolucionismo e a Antropologia Social: a Secularização do ritual em Usos e Costumes dos Bantos, de Henri Junod}

\section{RESUMO}

O conceito de "ritual de passagem", hoje largamente utilizado para descrever momentos de marcação social, significou um passo no sentido da secularização nos estudos dos rituais. Van Gennep, ao formulá-lo, pensou ainda no sagrado como objeto essencial do rito, mas deu instrumentos importantes para superar essa vinculação. Henri Junod, amigo de Van Gennep, missionário e etnógrafo, usou o conceito para dar unidade às suas descrições etnográficas, avançando assim no uso desse conceito para a compreensão da vida secular. Buscou-se demonstrar como o largo uso que Junod faz do conceito de ritual de passagem em sua etnografia Usos e Costumes dos Bantos, publicada entre 1912 e 1913, criou uma tensão com sua tentativa de aplicar as categorias mentalistas desenvolvidas por Tylor, Frazer, Marret e outros. Dessa forma, o trabalho de Junod aparece como uma expressão importante do conflito entre o evolucionismo e a então nascente Antropologia Social.

PALAVRAS-CHAVE: Henri-Alexandre Junod; Ritual; Ritos de Passagem; Crença; Etnografia.

\section{Between Evolutionism and Social Anthropology: The Secularization of Ritual in Henri Junod's Uses and Customs of the Bantu}

\section{ABSTRACT}

The concept of rite of passage, which has been widely used nowadays to describe social milestones, meant one step towards a secular view on the ritual studies. Although Van Gennep thought holiness as an essential ritual object when first enunciating this concept, he furnished important instruments to overcome this bound. Henri Junod, Van Gennep's friend, missionary and ethnographer; applied this concept to unify his ethnographic descriptions grasping the secular life. We try to demonstrate that the large application made by Junod of the "rite of passage" concept in his ethnography Life in South African Tribe (published between 1912 and 1913) tensions with his attempt to use the mentalist categories of Tylor, Frazer, Marret and others. Thus, Junod's work emerges as a important expression of the conflict between Evolucionism and the rising Social Anthropology.

KEYWORDS: Henri-Alexandre Junod; Ritual; Rites of Passage; Beliefs; Ethnography. 